Journal of Patient-Centered

\title{
Factors in Patient Responsiveness to Directional Preference- Matched Treatment of Neck Pain With or Without Upper Extremity Radiation
}

\author{
Benjamin Holmes \\ Ruta Brazauskas \\ Laura D. Cassidy \\ Rachel A. Wiegand
}

Follow this and additional works at: https://aah.org/jpcrr

Part of the Musculoskeletal Diseases Commons, Other Medical Specialties Commons, and the Other Rehabilitation and Therapy Commons

\section{Recommended Citation}

Holmes B, Brazauskas R, Cassidy LD, Wiegand RA. Factors in patient responsiveness to directional preference-matched treatment of neck pain with or without upper extremity radiation. J Patient Cent Res Rev. 2017;4:60-8. doi: 10.17294/2330-0698.1271

Published quarterly by Midwest-based health system Advocate Aurora Health and indexed in PubMed Central, the Journal of Patient-Centered Research and Reviews (JPCRR) is an open access, peer-reviewed medical journal focused on disseminating scholarly works devoted to improving patient-centered care practices, health outcomes, and the patient experience. 


\title{
Factors in Patient Responsiveness to Directional Preference-Matched Treatment of Neck Pain With or Without Upper Extremity Radiation
}

\author{
Benjamin Holmes, DC, ${ }^{1,2}$ Ruta Brazauskas, PhD, ${ }^{2}$ Laura D. Cassidy, PhD, ${ }^{2}$ Rachel A. Wiegand, DC 1 \\ ${ }^{1}$ Aurora Sheboygan Clinic Spine Institute, Sheboygan, WI; ${ }^{2}$ Institute for Health and Equity, Medical College of \\ Wisconsin, Milwaukee, WI
}
Purpose Patient-related predictive factors in responsiveness to directional preference therapy for neck pain with or without upper extremity radiation (NP/R) have not been reported. A directional preference is any neck movement that, when performed repeatedly to end range, results in centralization and/or alleviation of $\mathrm{NP} / \mathrm{R}$. It was hypothesized that patient compliance with a prescribed, directional preference-matched home exercise program would improve positive responsiveness to NP/R treatment.

Methods Patient-related factors thought to affect responsiveness to care were collected retrospectively from charts and de-identified for patients with NP/R who underwent chiropractic treatment at a multispecialty spine clinic from January 2014 through June 2015. Responsiveness was measured by calculating the percentage change in Neck Bournemouth Questionnaire (NBQ) scores over treatment time. Multiple linear regression was used to identify factors associated with positive responsiveness.

Results Mean percentage change in patient NBQ score from initial intake to discharge was 50\% (standard deviation: 32\%). Of 104 patients meeting study inclusion criteria, $86(83 \%)$ reported experiencing improvement after the first treatment session. Bivariate analysis of patient characteristics by compliance with directional preference-matched exercise indicated that compliant patients $(n=95,91 \%)$ demonstrated significantly greater responsiveness to care than did noncompliant patients, at $55 \%$ versus $25 \%$ change in NBQ score, respectively $(P=0.0041)$. Four factors were statistically significant predictors of patient responsiveness to directional preference therapy for NP/R: patient compliance with directional preference-matched exercise $(P=0.0023)$, patient age $(P=0.0029)$, condition chronicity $(P<0.0001)$, and whether the patient reported improvement of symptoms following initial treatment session $(P=0.0003)$.

Conclusions The results of this study suggest that patient compliance with directional preference exercise is associated with patient responsiveness to conservative treatment of NP/R, as are age, chronicity and report of immediate symptom improvement. (J Patient Cent Res Rev. 2017;4:60-68.)

Keywords neck pain; directional preference; Bournemouth questionnaire

$\mathrm{N}$ eck pain is common among adults, with global annual incidence rates reported between $10.4 \%$ and $21.3 \% .{ }^{1}$ It is the fourth leading cause of disability globally. ${ }^{2}$ Neck pain can

Correspondence: Benjamin Holmes, DC,

Aurora Sheboygan Clinic Spine Institute,

2414 Kohler Memorial Drive, Sheboygan, WI, 53081,

T: 920-457-4461, ext. 1608, Email: ben.holmes@aurora.org be accompanied by upper extremity radiation of pain, paresthesia, numbness or weakness, sometimes attributable to cervical radiculopathy. The annual ageadjusted cervical radiculopathy incidence rate in one large epidemiological survey in Minnesota was 83 per 100,000 persons. $^{3}$

Several conservative treatment options are available for neck pain, including "wait and see,"4 spinal mobilization or manipulation, home exercises, physical 
therapy modalities, medications and epidural steroid injection. Evidence of the efficacy of conservative management is tenuous. Some evidence suggests that exercise may be beneficial for neck pain. ${ }^{5}$ Studies supporting conservative management of neck pain with upper extremity radiation are even sparser, and randomized controlled trials are needed to examine the clinical effectiveness of conservative treatments. ${ }^{6}$

One conservative treatment approach is called directional preference therapy. Variations of directional preference therapy have been studied and performed under different monikers, namely the McKenzie approach $^{7}$ and mechanical diagnosis and therapy (MDT). ${ }^{4,8}$ Directional preference involves manual therapy, exercise therapy or both, which are predicated on the discovery of a "directional preference" during the physical examination. A directional preference is any specific neck movement that, when performed repeatedly to end range, results in centralization and/or alleviation of neck pain with or without upper extremity radiation (NP/R) as well as improved mechanical presentation (eg, improved active global range of motion). ${ }^{9}$ Once the preference has been ascertained, the directional preference practitioner may utilize, if necessary, the specific direction when performing manual therapy to the spine and match the direction in prescribing home exercises.

Eight clinical trials have assessed directional preference therapy in treating NP/R, ${ }^{7,10-16}$ but the trials lack definitive evidence of treatment efficacy. One systematic review assessed directional preference therapy for neck pain and concluded that directional preference therapy may not be significantly more effective than a "wait and see" approach for neck pain; however, skillset adequacy of the directional preference therapists in the included studies was questioned. ${ }^{4}$ Several studies have evaluated and supported directional preference therapy for lumbar spine pathology. ${ }^{17-23}$

This study evaluated characteristics of NP/R patients and responsiveness to directional preference therapy. Recognizing both the theoretical value of directional preference-matched home exercise performance and the capability of self-management in patient-centered care to improve health outcomes, the investigators conducting this study hypothesized that patient compliance with a prescribed, directional preferencematched home exercise program would improve responsiveness to conservative treatment of NP/R.

\section{METHODS}

The local institutional review board determined that this study, designed primarily as a quality assessment and improvement project, did not constitute human subject research.

A retrospective chart review was conducted for all patients who presented with axial NP/R and who demonstrated limited and/or painful active cervical range of motion, showed a directional preference on evaluation and underwent directional preference treatment by a single chiropractor at a spine clinic within a large health system from January 2014 through June 2015 ( $\mathrm{N}=245)$. Patients whose symptoms and signs did not satisfy the above diagnostic criteria, who were younger than 18 years, who suspended care prematurely or for whom outcome data were incomplete were excluded from the study. Data were de-identified prior to statistical analysis.

Aside from the chiropractor, this study's clinic team comprised an orthopedic spine surgeon, three orthopedic physician assistants and four pain proceduralists. Occasionally throughout the course of individual patient care, other treatment modalities were utilized as prescribed/performed by team physicians, assistants and proceduralists, including the prescription of anti-inflammatory, muscle relaxant, analgesic and anti-epileptic medication and epidural steroid injection. Treating members of the clinic team along with individual patients made the decision to utilize these modalities on a case-by-case basis. Anti-inflammatory, muscle relaxant and analgesic medications were prescribed in the presence of either neck pain alone or neck pain with upper extremity radiation. Anti-epileptic medication and epidural steroid injections were recommended only in cases of neck pain with upper extremity radiation.

Responsiveness to directional preference therapy was measured by changes in scores reported by the patient on the Neck Bournemouth Questionnaire (NBQ) pre- and post-treatment span. The NBQ is a reliable, 
responsive and efficient outcomes measurement tool (Figure 1) to assess the effects of patients' neck conditions on seven aspects of their lives: pain, activities of daily living, social activities, anxiety, depression, work and fear-avoidance beliefs, and locus of control. ${ }^{24-27}$

This study assessed patient compliance with prescribed directional preference-matched home exercises as a predictive factor of positive response to directional preference therapy. Other patient characteristics analyzed as factors in responsiveness were: age, body mass index, comorbidities of anxiety or depression, diagnosis, sex, whether the patient reported improvement immediately following the first treatment session, payor, treatment dosage, number of treatments throughout course of care, smoking status, condition chronicity, and prescription medication usage (including epidural steroid injection).

On initial presentation to the chiropractor, the patient complaining of neck pain with or without upper extremity pain, numbness, paresthesia or weakness underwent directional preference assessment. The directional preference assessment process is welldescribed in the literature, 9 (and a synopsis is provided in this paper's introduction). Following the ascertainment of a directional preference in the patient with $\mathrm{NP} / \mathrm{R}$, exercise and manual therapies matched to the preferred direction were performed. NBQ scores were assessed at intake and every 2-4 weeks thereafter until the patient's condition was determined fixed and stable, and the patient was released from care.

Occasionally, NP/R symptoms returned after the patient was released and care was reinitiated, creating a subsequent course of treatment. After the NBQ scores were collected, the percentage change was calculated, meaning the difference between a patient's NBQ score at intake and at the conclusion of the treatment course, divided by the score at intake, and multiplied by 100 , with positive percentages indicating improvement and negative percentages indicating decline. ${ }^{29}$

\section{Statistical Analysis}

Patient characteristics were summarized with descriptive statistics. Patient-related factors were compared between exercise-compliant and exercise- noncompliant groups using Wilcoxon rank-sum test for continuous variables and $\chi^{2}$ test for categorical variables.

Multiple linear regression analysis was used to model patient responsiveness to directional preference therapy in relation to: age; body mass index; comorbidities of anxiety and/or depression (as determined by presence of anxiety and/or depression diagnoses in the patient's electronic medical record); NP/R primary diagnosis variation (neck pain without upper extremity radiation or neck pain with upper extremity radiation); sex; reported improvement after first treatment session (yes or no); payor (commercial or noncommercial insurance, the latter of which includes self-pay, personal injury, workers' compensation, Medicaid and Medicare); reported compliance with the home exercise program as prescribed; treatment dosage (number of treatments per days of treatment span); total number of treatments throughout the course of care; smoking status; chronicity of symptoms (acute/ subacute or chronic/acute-on-chronic); and the use of prescription substances (anti-inflammatories, muscle relaxants, analgesics, anti-epileptics and/or epidural steroids). A backward elimination model selection procedure was used to identify statistically significant covariates to include in the model. Significance was defined as $\mathrm{P}<0.05$ throughout. SAS OnDemand for Academics software (SAS Institute, Cary, NC) was used to perform statistical analysis.

\section{RESULTS}

A total of 104 patients, undergoing a total of 119 treatment courses, met the inclusion criteria and were included in the analysis. The largest number of treatment courses per patient was four (which occurred in 1 patient); 8 of the 104 patients underwent two treatment courses and 2 patients underwent three courses. The average number of treatment sessions per course of care was 6.8 (Table 1). For analysis purposes, only a patient's first treatment course of NP/R was considered.

Also shown in Table 1, the mean age of study population was 47 years (standard deviation: 12.0), and $68 \%$ of patients were female. The mean change in NBQ score with respect to initial reported score was $50 \% \pm 32 \%$; 86 patients $(83 \%)$ reported experiencing 
BOURNEMOUTH QUESTIONNAIRE (NECK PAIN)

Put a CROSS in ONE box for EACH of the following statements that best describes your neck pain and how it is affecting you NOW. Please read each question carefully before answering.

Q1 Over the past few days, on average, how would you rate your neck pain on a scale where '0' is 'no pain' and ' 10 ' is 'worst pain possible'?

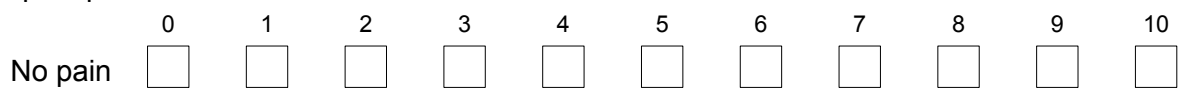

Q2 Over the past few days, on average, how has your neck pain interfered with your daily activities (housework, washing, dressing, lifting, reading, driving, sleeping) on a scale where ' 0 ' is 'no interference' and ' 10 ' is 'completely unable to carry on with normal day-to-day activities'?

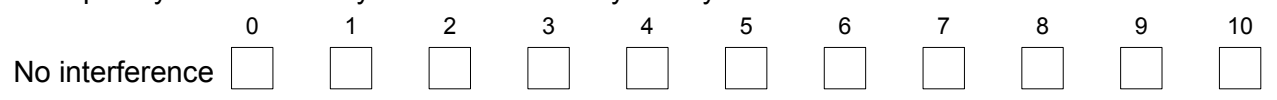

Q3 Over the past few days, on average, how much has your neck pain interfered with your normal social routine including recreational, social and family activities, on a scale where ' 0 ' is 'no interference' and '10' is 'completely unable to participate in any social and recreational activity'?

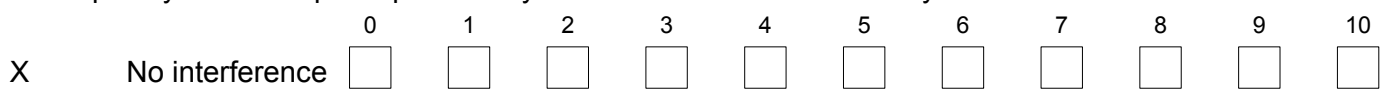

Q4 Over the past few days, on average, how anxious (uptight, tense, irritable, difficulty in relaxing/concentrating) have you been feeling, on a scale where ' 0 ' is 'not at all anxious' and '10' is 'extremely anxious'?

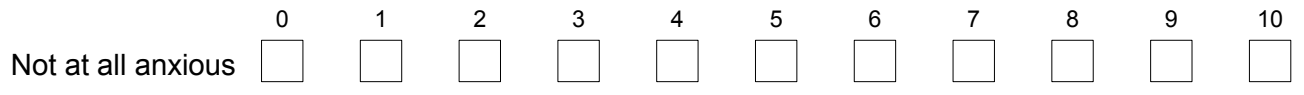

Q5 Over the past few days, how depressed (down-in-the-dumps, sad, in low spirits, pessimistic, lethargic) have you been feeling, on a scale where ' 0 ' is 'not at all depressed' and '10' is 'extremely depressed'?

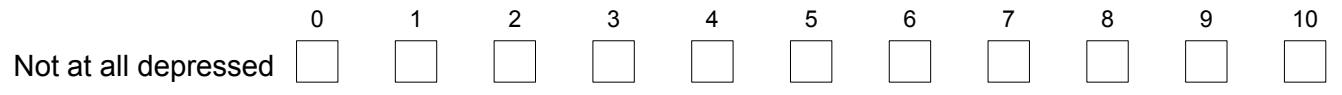

Q6 Over the past few days, how do you think your work (both inside the home and/or employed work) have affected your neck pain, on a scale where ' 0 ' is 'make it no worse' and '10 is 'make it very much worse'?

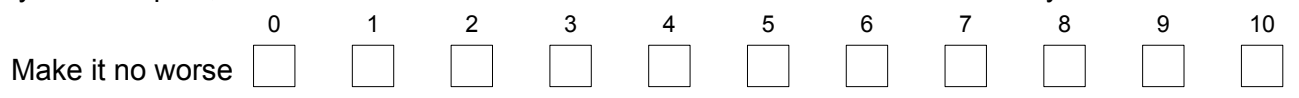

Q7 Over the past few days, on average, how much have you been able to control (help/reduce) and cope your neck pain on your own, on a scale where ' 0 ' is 'I can control it completely' and ' 10 ' is 'I have no control whatsoever'?

I have complete control over my pain
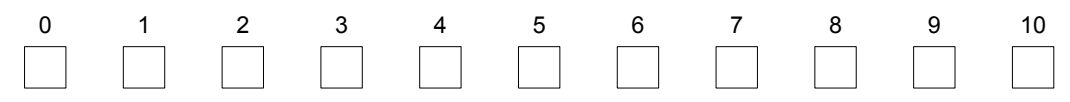

THANK YOU VERY MUCH FOR YOUR TIME IN COMPLETING THIS QUESTIONNAIRE

Figure 1. Neck Bournemouth Questionnaire. (Republished from http://www.aecc.ac.uk/, with permission from the Anglo-European College of Chiropractic [Bournemouth, United Kingdom] and author Jennifer E. Bolton. 
Table 1. Patient Characteristics

\begin{tabular}{|c|c|}
\hline Characteristic & $\begin{array}{c}\text { Patient } \\
\text { population } \\
(\mathrm{N}=104)\end{array}$ \\
\hline Mean age, years \pm SD & $46.8 \pm 12.0$ \\
\hline Age < 55 years, $\mathrm{n}(\%)$ & $75(72 \%)$ \\
\hline Age $\geq 55$ years, $n(\%)$ & $29(28 \%)$ \\
\hline Mean body mass index \pm SD & $28.3 \pm 7.2$ \\
\hline $\begin{array}{l}\text { Mean percentage change in } \\
\text { questionnaire score with respect } \\
\text { to initial score } \pm S D\end{array}$ & $50 \% \pm 32 \%$ \\
\hline Patients with anxiety, n (\%) & $29(28 \%)$ \\
\hline Patients with depression, (\%) & $31(30 \%)$ \\
\hline \multicolumn{2}{|l|}{ Diagnosis } \\
\hline Neck pain without UE radiation, n (\%) & $62(60 \%)$ \\
\hline Neck pain with UE radiation, n (\%) & $42(40 \%)$ \\
\hline \multicolumn{2}{|l|}{ Sex } \\
\hline Female, n (\%) & $71(68 \%)$ \\
\hline Male, n (\%) & $33(32 \%)$ \\
\hline $\begin{array}{l}\text { Patients who experienced } \\
\text { improvement following first } \\
\text { treatment session, n (\%) }\end{array}$ & $86(83 \%)$ \\
\hline \multicolumn{2}{|l|}{ Payor } \\
\hline Commercial, n (\%) & $91(87.5 \%)$ \\
\hline $\begin{array}{l}\text { Noncommercial (self, personal } \\
\text { injury, workers' compensation, } \\
\text { Medicaid, Medicare), n (\%) }\end{array}$ & $13(12.5 \%)$ \\
\hline $\begin{array}{l}\text { Patient compliance with directional } \\
\text { preference-matched home } \\
\text { exercise program, } \mathrm{n}(\%)\end{array}$ & $95(91 \%)$ \\
\hline $\begin{array}{l}\text { Mean treatment dosage, number } \\
\text { of treatments per days of } \\
\text { treatment span } \pm S D\end{array}$ & $0.2 \pm 0.1$ \\
\hline $\begin{array}{l}\text { Mean number of treatments per } \\
\quad \text { episode } \pm \text { SD }\end{array}$ & $6.8 \pm 4.5$ \\
\hline Patients who smoke, n (\%) & $20(19 \%)$ \\
\hline \multicolumn{2}{|l|}{ Chronicity } \\
\hline Acute/subacute, n (\%) & $39(37.5 \%)$ \\
\hline Chronic/acute-on-chronic, n (\%) & $65(62.5 \%)$ \\
\hline \multicolumn{2}{|l|}{ Prescription substances } \\
\hline Anti-inflammatory, n (\%) & $32(31 \%)$ \\
\hline Muscle relaxant, n (\%) & $28(27 \%)$ \\
\hline Analgesic, n (\%) & $22(21 \%)$ \\
\hline Anti-epileptic, n (\%) & $9(9 \%)$ \\
\hline Epidural steroids, n (\%) & $10(10 \%)$ \\
\hline
\end{tabular}

$S D$, standard deviation; UE, upper extremity. improvement after the first treatment session, and 95 patients $(91 \%)$ reported being compliant with the prescribed home exercise program. A majority of patients $(n=65,62.5 \%)$ suffered from chronic or acute-on-chronic pain as opposed to acute/subacute pain. Chronic pain was defined as neck and/or upper extremity pain that had been persistent for greater than 3 months, acute pain defined as less than 7 days, subacute pain defined as lasting between 7 days and 3 months, and acute-on-chronic pain defined as a flare-up of acute or subacute pain in the presence of underlying chronic pain.

Table 2 shows the results of the bivariate analysis of patient characteristics by compliance with prescribed directional preference-matched home exercise. Exercise-compliant patients ("exercisers") demonstrated significantly improved responsiveness to care compared with noncompliant patients ("nonexercisers"), with a $55 \%$ and $25 \%$ change in NBQ score, respectively $(\mathrm{P}=0.0041)$. Only $25 \%$ of exercisers experienced depression compared with $78 \%$ of nonexercisers $(\mathrm{P}=0.0010)$. Payor classification varied significantly between the two groups as well $91 \%$ of exercisers were commercially insured, whereas $44 \%$ of nonexercisers were noncommercially insured $(\mathrm{P}=0.0024)$. No statistically significant difference between exercisers' and nonexercisers' chronicity of symptoms was found.

Results of multiple linear regression are summarized in Table 3. Compliance with a prescribed directional preference-matched home exercise program was positively associated with responsiveness to directional preference therapy $(\mathrm{P}=0.0023)$, and condition chronicity was negatively associated $(\mathrm{P}<0.0001)$. Patient age $\geq 55$ years and noted improvement of symptoms following the initial treatment session also were both positively associated with responsiveness to therapy $(\mathrm{P}=0.0029$ and $\mathrm{P}=0.0003$, respectively).

Patient responsiveness to directional preference therapy based on combinations of patient characteristics within the best-fit linear regression was estimated (Table 4). Analysis was repeated to include all treatment episodes. Results of this secondary analysis (data not shown) were very similar to the presented analysis, which involved only the first treatment episode. 
Table 2. Patient Characteristics by Compliance With Prescribed Home Exercises

\begin{tabular}{|c|c|c|c|}
\hline Characteristic & Exercisers $(n=95)$ & Nonexercisers $(n=9)$ & $P$ \\
\hline Median BMI (range) & $27(18-55)$ & $28(20-42)$ & 0.2883 \\
\hline Median percentage change in score (range) & $55 \%(-18 \%-100 \%)$ & $25 \%(-44 \%-69 \%)$ & 0.0041 \\
\hline $\begin{array}{l}\text { Age } \\
\qquad \text { Age }<55 \text { years, } n(\%) \\
\text { Age } \geq 55 \text { years, } n(\%)\end{array}$ & $\begin{array}{l}70(74 \%) \\
25(26 \%)\end{array}$ & $\begin{array}{l}5(56 \%) \\
4(44 \%)\end{array}$ & 0.7306 \\
\hline Patients with anxiety, $\mathrm{n}(\%)$ & $24(25 \%)$ & $5(56 \%)$ & 0.0528 \\
\hline Patients with depression, $\mathrm{n}(\%)$ & $24(25 \%)$ & $7(78 \%)$ & 0.0010 \\
\hline $\begin{array}{l}\text { Diagnosis } \\
\text { Neck pain without UE radiation, n (\%) } \\
\text { Neck pain with UE radiation, } \mathrm{n}(\%)\end{array}$ & $\begin{array}{l}57(60 \%) \\
38(40 \%)\end{array}$ & $\begin{array}{l}5(56 \%) \\
4(44 \%)\end{array}$ & 0.7951 \\
\hline $\begin{array}{l}\text { Sex } \\
\text { Female, } \mathrm{n}(\%) \\
\text { Male, } \mathrm{n}(\%)\end{array}$ & $\begin{array}{l}64(67 \%) \\
31(33 \%)\end{array}$ & $\begin{array}{l}7(78 \%) \\
2(22 \%)\end{array}$ & 0.5214 \\
\hline Improvement following first session, $\mathrm{n}(\%)$ & $80(84 \%)$ & $6(67 \%)$ & 0.1836 \\
\hline $\begin{array}{l}\text { Payor } \\
\text { Commercial, n (\%) } \\
\text { Noncommercial, n (\%) }\end{array}$ & $\begin{array}{c}86(91 \%) \\
9(9 \%)\end{array}$ & $\begin{array}{l}5(56 \%) \\
4(44 \%)\end{array}$ & 0.0024 \\
\hline Median treatment dosage, n/day (range) & $0.1(0.03-0.5)$ & $0.1(0.03-0.3)$ & 0.0988 \\
\hline Median treatments per episode, $n$ (range) & $6(2-30)$ & $4(3-7)$ & 0.0101 \\
\hline Patients who smoke, n (\%) & $17(18 \%)$ & $3(33 \%)$ & 0.2614 \\
\hline $\begin{array}{l}\text { Chronicity } \\
\text { Acute/subacute, n (\%) } \\
\text { Chronic/acute-on-chronic, n (\%) }\end{array}$ & $\begin{array}{l}37(39 \%) \\
58(61 \%)\end{array}$ & $\begin{array}{l}2(22 \%) \\
7(78 \%)\end{array}$ & 0.3219 \\
\hline \multicolumn{4}{|l|}{ Prescription medication } \\
\hline Anti-inflammatory, n (\%) & $31(33 \%)$ & $1(11 \%)$ & 0.1812 \\
\hline Muscle relaxant, $\mathrm{n}(\%)$ & $24(25 \%)$ & $4(44 \%)$ & 0.2150 \\
\hline Analgesic, $\mathrm{n}(\%)$ & $20(21 \%)$ & $2(22 \%)$ & 0.9346 \\
\hline Anti-epileptic, n (\%) & $7(7 \%)$ & $2(22 \%)$ & 0.1298 \\
\hline Epidural steroids, n (\%) & $8(8 \%)$ & $2(22 \%)$ & 0.1795 \\
\hline
\end{tabular}

$B M I$, body mass index; UE, upper extremity.

\section{DISCUSSION}

The general agreement among health scientists is that patient engagement and participation in health care, such as via home exercise performance, are beneficial; however, clinical trials and reviews specifically evaluating directional preference therapy for NP/R are sparse and insufficiently informative. While the results of this study are consistent with previous studies that support the use of directional preference therapy in treating NP/R, ${ }^{7,10-16}$ our results also explicate specific patient-related factors in responsiveness to directional preference therapy outside the practitioner-related factors studied prior. For instance, these findings suggest a possible mechanism behind limited responsiveness of neck pain patients to directional preference therapy reported in the systematic review by Takasaki and May, ${ }^{4}$ as 61 of the 100 patients from two of the five trials studied by the authors had suffered from neck pain for more than 3 months. Our finding that chronicity of symptoms is a predictive factor in patient responsiveness to care may provide an explanation of limited responsiveness to directional preference therapy in those two trials.

This study has limitations. Several data points are patient-reported, such as NBQ scores, chronicity, improvement following initial treatment session, compliance with directional preference home 
Table 3. Multivariate Analysis of Change in NBQ Score

\begin{tabular}{|c|c|c|}
\hline Variable & Coefficient (SE) & $P$ \\
\hline Intercept & $19 \%(10 \%)$ & 0.0614 \\
\hline Compliance with home exercise & $21 \%(7 \%)$ & 0.0023 \\
\hline Chronicity of symptoms & $-23 \%(5 \%)$ & $<0.0001$ \\
\hline Patient age $\geq 55$ years & $17 \%(6 \%)$ & 0.0029 \\
\hline Improvement following initial treatment session & $22 \%(6 \%)$ & 0.0003 \\
\hline
\end{tabular}

NBQ, Neck Bournemouth Questionnaire; SE, standard error.

Table 4. Estimated Patient Responsiveness to Directional Preference Therapy

\begin{tabular}{|c|c|c|c|c|}
\hline $\begin{array}{l}\text { Compliance with home } \\
\text { exercise (yes or no) }\end{array}$ & $\begin{array}{c}\text { Chronicity of symptoms } \\
\text { (chronic/acute-on-chronic or } \\
\text { acute/subacute) }\end{array}$ & $\begin{array}{l}\text { Age } \geq 55 \\
\text { years }\end{array}$ & $\begin{array}{c}\text { Improvement } \\
\text { following initial } \\
\text { treatment session }\end{array}$ & $\begin{array}{c}\text { Estimated } \\
\text { responsiveness }\end{array}$ \\
\hline No & Chronic/acute-on-chronic & No & No & $-4 \%$ \\
\hline No & Chronic/acute-on-chronic & Yes & No & $13 \%$ \\
\hline No & Acute/subacute & No & No & $18 \%$ \\
\hline No & Chronic/acute-on-chronic & No & Yes & $17 \%$ \\
\hline No & Acute/subacute & Yes & No & $36 \%$ \\
\hline No & Chronic/acute-on-chronic & Yes & Yes & $34 \%$ \\
\hline No & Acute/subacute & No & Yes & $40 \%$ \\
\hline No & Acute/subacute & Yes & Yes & $57 \%$ \\
\hline Yes & Chronic/acute-on-chronic & No & No & $16 \%$ \\
\hline Yes & Chronic/acute-on-chronic & Yes & No & $33 \%$ \\
\hline Yes & Acute/subacute & No & No & $39 \%$ \\
\hline Yes & Chronic/acute-on-chronic & No & Yes & $38 \%$ \\
\hline Yes & Acute/subacute & Yes & No & $59 \%$ \\
\hline Yes & Chronic/acute-on-chronic & Yes & Yes & $55 \%$ \\
\hline Yes & Acute/subacute & No & Yes & $61 \%$ \\
\hline Yes & Acute/subacute & Yes & Yes & $78 \%$ \\
\hline
\end{tabular}

exercises and smoking status. These data are subjective reports and potentially carry social desirability bias (for example, the underreporting of smoking and overreporting of exercise compliance). Also, some of these reports relate to the patient's experience with pain. Because pain and its effects are a subjective experience, some level of subjectivity is inescapable. Nevertheless, by comparing percentage change of NBQ scores - which are intrapersonal ratios and therefore control for personalization ${ }^{30}$ of the pain experience - instead of raw NBQ scores, data volatility is maximally neutralized and interpersonal comparability maximally facilitated. Small patient numbers limited some comparisons, particularly regarding nonexercisers.

Because the study population was predominantly Caucasian and commercially insured - a make-up that accurately reflects the overall patient population at our clinic - findings are not generalizable. However, they will inform processes to assess and improve quality at our institution (and perhaps those that are similar) as well as motivate and guide further research of directional preference therapy for 
$\mathrm{NP} / \mathrm{R}$. These findings may inform further assessment of larger samples in more demographically diverse settings. Dissemination of these results may motivate patients to comply with directional preference home exercises and also encourage regional clinicians to enlist patient involvement when treating NP/R. Local directional preference practitioners also can use these findings to inform themselves and patients of likelihood of responsiveness to care at the early outset of treatment, which could be financially, emotionally and therapeutically beneficial to the patient.

\section{CONCLUSIONS}

Patient compliance with directional preference exercise is associated with patient responsiveness to directional preference therapy in conservative care treatments of neck pain. Patients 55 years of age or older, those with acute/subacute chronicity and those who report symptom improvement following the first treatment session showed significant improvement. Implementation of these findings could improve care of patients with neck pain, with or without upper extremity radiation, at a local level.

\section{Patient-Friendly Recap}

- Patients experiencing persistent neck pain with or without arm symptoms have several treatments at their disposal. Often, a conservative course of "directional preference" therapy is chosen.

- Directional preference refers to neck movements that, when performed repeatedly, result in centralization or alleviation of pain. Patients using directional preference therapy may be assigned home exercises as part of their treatment plan.

- The authors found that compliance with these exercises, along with patient factors such as age $\geq 55$ and noted improvement after initial treatment session, contributed significantly to success of therapy.

\section{Conflicts of Interest}

None.

\section{References}

1. Hoy DG, Protani M, De R, Buchbinder R. The epidemiology ofneck pain. Best Pract Res Clin Rheumatol. 2010;24:783-92. $\underline{\text { CrossRef }}$

2. Cohen S. Epidemiology, diagnosis, and treatment of neck pain. Mayo Clin Proc. 2015;90:284-99. CrossRef

3. Radhakrishnan K, Litchy WJ, O'Fallon WM, Kurland LT. Epidemiology of cervical radiculopathy. A populationbased study from Rochester, Minnesota, 1976 through 1990. Brain. 1994;117:325-35. CrossRef

4. Takasaki H, May S. Mechanical diagnosis and therapy has similar effects on pain and disability as 'wait and see' and other approaches in people with neck pain: a systematic review. J Physiother. 2014;60:78-84. CrossRef

5. Gross A, Kay TM, Paquin JP, et al. Exercises for mechanical neck disorders. Cochrane Database Syst Rev. 2015;1:CD004250. CrossRef

6. Gebremariam L, Koes BW, Peul WC, Huisstede BM. Evaluation of treatment effectiveness for the herniated cervical disc. Spine. 2012;37:E109-18. CrossRef

7. May S, Gardiner E, Young S, Klaber-Moffett J. Predictor variables for a positive long-term functional outcome in patients with acute and chronic neck and back pain treated with a McKenzie approach: a secondary analysis. J Man Manip Ther. 2008;16:155-60. CrossRef

8. Donelson R. Mechanical diagnosis and therapy for radiculopathy. Phys Med Rehabil Clin N Am. 2011;22:75-89. CrossRef

9. McKenzie R, May S. The Cervical \& Thoracic Spine: Mechanical Diagnosis \& Therapy, Second Edition. Waikanae, New Zealand: Spinal Publications New Zealand Ltd, 2006, p. 86.

10. Rasmussen C, Rechter L, Schmidt I, Hansen VK, Therkelsen K. The association of the involvement of financial compensation with the outcome of cervicobrachial pain that is treated conservatively. Rheumatology (Oxford). 2001;40:552-4. CrossRef

11. Moffett JK, Jackson DA, Gardiner ED, et al. Randomized trial of two physiotherapy interventions for primary care neck and back pain patients: 'McKenzie' vs brief physiotherapy pain management. Rheumatology (Oxford). 2006;45:1514-21. $\underline{\text { CrossRef }}$

12. Kjellman G, Oberg B. A randomised clinical trial comparing general exercise, McKenzie treatment and a control group in patients with neck pain. J Rehabil Med. 2002;34:183-90.

13. Guzy G, Frańczuk B, Krąkowska A. A clinical trial comparing the McKenzie method and a complex rehabilitation program in patients with cervical derangement syndrome. J Orthop Trauma Surg Rel Res. 2011;2:32-8.

14. Kongsted A, Qerama E, Kasch H, et al. Neck collar, "actas-usual" or active mobilization for whiplash injury? A randomized parallel trial. Spine (Phila Pa 1976). 2007;32:618-26.

15. Rosenfeld M, Seferiadis A, Carlsson J, Gunnarsson R. Active intervention in patients with whiplash-associated disorders improves long-term prognosis: a randomized controlled clinical trial. Spine. 2003;28:2491-8. CrossRef 
16. Singh P, Gupta K. Comparative study of a structured progressive exercise program and McKenzie protocol in individuals with mechanical cervical spine pain. Physiother Occup Ther J. 2012;5:11-7.

17. Balkovec C, McGill S. Extent of nucleus pulposus migration in the annulus of porcine intervertebral discs exposed to cyclic flexion only versus cyclic flexion and extension. Clin Biomech (Bristol, Avon). 2012;27:766-70. CrossRef

18. Takasaki H, May S, Fazey PJ, Hall T. Nucleus pulposus deformation following application of mechanical diagnosis and therapy: a single case report with magnetic resonance imaging. J Man Manip Ther. 2010;18:153-8. CrossRef

19. Beattie PF, Arnot CF, Donley JW, Noda H, Bailey L. The immediate reduction in low back pain intensity following lumbar joint mobilization and prone press-ups is associated with increased diffusion of water in the L5-S1 intervertebral disc. J Orthop Sports Phys Ther. 2010;40:256-64. CrossRef

20. Zou J, Yang H, Miyazaki M, et al. Dynamic bulging of intervertebral discs in the degenerative lumbar spine. Spine (Phila Pa 1976). 2009;34:2545-50. CrossRef

21. Tsantrizos A, Ito K, Aebi M, Steffen T. Internal strains in healthy and degenerated lumbar intervertebral discs. Spine (Phila Pa 1976). 2005;30:2129-37. CrossRef

22. Clare HA, Adams R, Maher CG. Reliability of McKenzie classification of patients with cervical or lumbar pain. J Manipulative Physiol Ther. 2005;28:122-7. CrossRef

23. Hefford C. McKenzie classification of mechanical spinal pain: profile of syndromes and directions of preference. Man Ther. 2008;13:75-81. CrossRef
24. Bolton JE, Humphreys BK. The Bournemouth Questionnaire: a short-form comprehensive outcome measure. II. Psychometric properties in neck pain patients. J Manipulative Physiol Ther. 2002;25:141-8. CrossRef

25. Irgens P, Lothe LR, Kvammen OC, Field J, Newell D. The psychometric profile of chiropractic patients in Norway and England: using and comparing the generic versions of the STarT Back 5-item screening tool and the Bournemouth Questionnaire. Chiropr Man Therap. 2013;21:41. CrossRef

26. Peterson C, Bolton J, Humphreys BK. Predictors of outcome in neck pain patients undergoing chiropractic care: comparison of acute and chronic patients. Chiropr Man Therap. 2012;20:27. CrossRef

27. Gay RE, Madson TJ, Cieslak KR. Comparison of the Neck Disability Index and the Neck Bournemouth Questionnaire in a sample of patients with chronic uncomplicated neck pain. J Manipulative Physiol Ther. 2007;30:259-62. CrossRef

28. Spanos G, Zounis M, Natsika M, May S. The application of mechanical diagnosis and therapy and changes on MRI findings in a patient with cervical radiculopathy. Man Ther. 2013;18:606-10. CrossRef

29. Hurst H, Bolton J. Assessing the clinical significance of change scores recorded on subjective outcome measures. J Manipulative Physiol Ther. 2004;27:26-35. CrossRef

30. Toombs SK (ed). Handbook of Phenomenology and Medicine. Dordrecht, The Netherlands: Kluwer Academic Publishers, 2001, p. 379.

(C) 2017 Aurora Health Care, Inc. 